migrations and emphasized the potential interest of further work.

Although the concepts of sea-floor spreading and plate tectonics were beginning to influence marine geology, the symposium dealt chiefly with sediments. Lisitzin's paper on the distribution and geochemistry of sediments was based largely on Soviet material, and Funnel, using all the data he could find, showed that although only the barest start had been made, the seemingly uncomplicated distribution of the principal water masses seemed to offer unique possibilities in micropalaeontology.

There is no written summary of the discussion that followed the symposium, but the general conclusion was that the South Pacific ocean offered great opportunities for advanced scientific study and that the planning would best be done by the laboratories that could carry out the work.

G. E. R. Deacon

\section{STRATIGRAPHICAL JOURNAL}

\section{Newsletters on Stratigraphy}

Vol. 1, No. 1. Edited by Gerd Lüttig. Quarterly. (Brill: Leiden, March 1970.) Hfl 64 per volume.

"OH no, here comes another periodical again!" These are the editor's own words recited in the preface to the first issue of Newsletters on Stratigraphy, adding yet another journal to the profusion of geological periodicals. And yet he makes a convincing and, I think, valid argument for introducing this international journal.

At the present time there is something of a rennaissance in stratigraphical thought. This re-vitalization follows a period when many of the earlier stratigraphical practices were questioned, when essentially stratigraphical studies were carried out under the guise of other branches of geological science and when stratigraphy was usually regarded as an out-moded aspect of geology. With the development of recent concepts in stratigraphy it has become necessary to redefine stratigraphical nomenclature, to reconsider the placing of stratigraphical boundaries and, above all, to reach international agreement on all major decisions. With the wealth of national and international committees erected to meet these ends this journal comes at a most opportune time to bring to the notice of other geologists the deliberations of these bodies and to allow minority views to be voiced.

In addition, the journal aims to cater for all stratigraphical studies with an international flavour, both as original publications and as stratigraphical extracts of papers appearing elsewhere with other aims in view. The editors also invite discussion of papers appearing not only within its own covers but of stratigraphical work from any source. We are told that papers will be brief and will be of "newsletter" form in that only indis. pensable figures will be accepted. English language is recommended but articles in German, French and Spanish will also be accepted provided they include an abstract in English.

Thus the aims of the journal are clear and exemplary; but how well does the reality match the theory? It is perhaps unreasonable to make a judgment on the first issue alone; clearly, no discussion has or could have been included. But, in an international publication one would have hoped for a more balanced set of contributors; all six contributions come from the Federal Republic of Germany, in spite of the fact that the board of associate editors is undoubtedly international. Of the papers appearing in this first issue two are concerned with the principles of stratigraphic nomenclature; neither presents an orthodox view. Two other papers discuss boundary problems on an international level. That dealing with the Cambrian/Ordovician boundary incorporates some very interesting new faunal information but fails to come to terms with the essential problem of defining the boundary. The fifth paper discusses the stratigraphical value of the echinoids in the Upper Cretaceous.

Having read the first number of Newsletters of Stratigraphy I was left with a sense of anticlimax, but also of anticipation of a more stimulating second number.

\section{R. A. GAYer}

\section{ADSORPTION CHEMISTRY}

\section{The Theory of Adsorption and Catalysis}

By Alfred Clark. (Physical Chemistry: a Series of Monographs.) Pp. $x+418$. (Academic: New York and London, August 1970.) $182 s$.

THE widely used and fruitful scientific procedure of postulating a model for a system of interest and then calculating some experimentally-measurable properties is well suited to dealing with adsorption phenomena. This procedure is followed by the author of this book, whose presentation shows clearly how the level of mathematical rigour which can be used declines on moving from physical adsorption through chemisorption to catalysis. In the first third of the book, which deals with physical adsorption, a logical sequence of models is presented, passing from localized non-interacting particles to localized interacting particles and ending with the two-dimensional adsorbed gas. A statistical mechanical approach is followed and a moderate knowledge of this subject is necessary if this part of the book is to be read with profit.

Unfortunately, the phenomena associated with chemisorption are at present susceptible neither to detailed statistical thermodynamic calculations nor to an $a b$ initio quantum mechanical treatmont. But the author presents clearly the simplified calculations which make some com. parisons of theory and experiment possible. In catalysis yet more empiricism is encountered, but we are given as logical and coherent an account of current theories as is possible at present.

One particularly pleasing feature of this book is the author's custom of presenting, where appropriate, a brief general account of a subject before developing in detail the particular aspect of it relevant to adsorption. For example, localized physical adsorption in which neighbouring molecules interact can, in principle, lead to a phase transition in the adsorbed gas. A short account of phase transitions in other, more familiar, situations enables the reader to see the particular case in perspective.

I think that this book will appeal to those who have a detailed interest in the theory of the interactions which govern adsorption behaviour. I found it interesting, well written and well produced. $\quad$ R. P. H. GASSER

\section{DERIVATIVES OF NH}

\section{Nitrenes}

Edited by Walter Lwowski. (Reactive Intermediates in Organic Chemistry.) Pp. xi +457 . (Wiley (Interscience): New York and London, August 1970.) 220s.

THERE has been much recent documentation in both books and reviews of the more familiar reactive intermediates of organic chemistry-carbonium ions, carbanions, radicals, carbenes and benzynes-but nitrenes have received relatively scant attention; this deficiency has now been handsomely corrected, and these derivatives of the electroneutral molecule, $\mathrm{NH}$, have at last come into their own.

There has in the past been some confusion over the naming of nitrenes, but the use of my definition in the first paragraph permits their ready designation as, for 